\title{
Characterization of Botrytis cinerea from Table Grapes in Chile Using RAPD-PCR
}

\author{
J. R. Thompson and B. A. Latorre, Departamento de Fruticultura y Enología, Facultad de Agronomía e Ingeniería \\ Forestal, Pontificia Universidad Católica, Casilla 306-22, Santiago, Chile
}

\begin{abstract}
Thompson, J. R., and Latorre, B. A. 1999. Characterization of Botrytis cinerea from table grapes in Chile using RAPD-PCR. Plant Dis. 83:1090-1094.

Random amplified polymorphic DNA (RAPD) analysis was performed on 29 isolates of Botrytis cinerea Pers. ex Fr. isolated from table grapes (Vitis vinifera L.) and other crops in Chile with 29 decaprimers. No single primer was found to differentiate either the host or the geographical origin of each of the B. cinerea isolates tested. The DNA profiles obtained, particularly with primers OPA4 and OPA11, distinguished isolates of $B$. cinerea from other epiphyte fungi found on table grapes, including Alternaria alternata, Aspergillus niger, Cladosporium herbarum, Epiccocum nigrum, Rhizopus stolonifer, a Penicillium sp., and yeasts (Cryptococcus laurentii, Rhodotorula glutinis, and Saccharomyces cerevisiae). Regardless of host origin, primers OPA4 and OPA11 amplified a strong fragment of 1.2 kilobases $(\mathrm{kb})$ and two fragments of 1.10 and $0.7 \mathrm{~kb}$, respectively. These DNA fragments were obtained even when only one conidium of $B$. cinerea was in the test sample. Three main groups were clearly defined based on the genetic similarities found in additional RAPD analysis with 19 arbitrary decaprimers and 15 selected isolates of $B$. cinerea. The overall similarity coefficients (SC) between the groups obtained ranged from 0.326 to 0.891 . Interestingly, all isolates from table grapes were included in group I (SC: 0.761 to 0.826 ), isolates from apple and tomato were in group II (SC: 0.739 to 0.848 ), while isolates from blueberry were either in group I (SC: 0.804) or III (SC: 0.673 ). Consequently, the genetic variability determined by RAPD analysis among these $B$. cinerea isolates suggested a possible host:pathogen relationship. However, further research is needed to clarify its pathological significance.
\end{abstract}

Additional keywords: apple, blueberry, Botryotinia fuckeliana, Botrytis bunch rot, gray mold, tomato

Botrytis cinerea Pers.:Fr. (teleomorph: Botryotinia fuckeliana (de Bary) Whetzel) is the cause of Botrytis bunch rot of table grapes (Vitis vinifera L.). Significant losses occur when long periods of high relative humidity $(>95 \%)$ or wetness and cool temperatures $\left(15\right.$ to $\left.22^{\circ} \mathrm{C}\right)$ coincide with blossoming and ripening (soluble solids $>8 \%$; $1,2,9,11)$. Besides grapes, $B$. cinerea infects a wide range of important vegetable, ornamental, bulb, and fruit crops in temperate regions, colonizing and surviving on senescing and dead plant tissues $(2,9,12)$. Host specialization has not been reported among populations of $B$. cinerea, but differences in virulence toward one given host plant has been observed $(4,5,19)$.

Corresponding author: B. A. Latorre

E-mail: blatorre@puc.cl

This project was funded in part by FONDEF D97I-1011.

Accepted for publication 18 August 1999.

Publication no. D-1999-1004-03R

(C) 1999 The American Phytopathological Society
Molecular techniques based on the polymerase chain reaction (PCR; 17,18) have been used as a tool in genetic mapping, molecular taxonomy, evolutionary studies, and diagnosis of several fungal species. The analysis of DNA products generated through random amplified polymorphic DNA (RAPD) has provided information on variation (10) and segregation (16) of genetic traits among strains of $B$. cinerea. Restriction fragment length polymorphism (RFLP) analysis has also revealed important genetic variation in $B$. cinerea, suggesting the presence of two species $(6,8)$. The objectives of this work were to characterize both intra- and interspecies isolates of $B$. cinerea from table grapes in Chile, using RAPD, and to identify specific markers to distinguish $B$. cinerea from epiphyte fungi commonly associated with table grapes.

\section{MATERIALS AND METHODS}

Fungal isolates. A total of 19 singlespore isolates of $B$. cinerea were established from samples of grape berries collected at harvest from commercial 'Thompson Seedless' vineyards in the Aconcagua Valley and Central Valley of
Chile. B. cinerea was also isolated from lettuce (Lactuca sativa L.) and from fruits of blueberry (Vaccinium corymbosum L.), apple (Malus communis DC.), kiwifruit (Actinidia chinensis Planchon), tomato (Lycopersicon esculentum Mill.), and pear (Pyrus communis L.). With the exception of isolates from blueberry, all $B$. cinerea isolates were obtained during the 1997 to 1998 growing season from samples collected in the same geographical region, across an area of about $200 \mathrm{~km}$ from north to south where most of the fruit and vegetable crops are cultivated. Those from blueberry were obtained in southern Chile (Gorbea, Temuco) in 1998. Isolates of several fungi found as epiphytes on table grapes in Chile were included to established the specificity of the RAPD primers. The fungi included: Alternaria alternata (Fr.:Fr) Keissl., Aspergillus niger Teigh., Cryptococcus laurentii (Kuff.) C. E. Skinner, Cladosporium herbarum (Pers.:Fr.) Link., Epicoccum nigrum Link ex. Fr., a Penicillium sp., Rhizopus stolonifer (Ehrenb.:Fr) Vuill, Rhodotorula glutinis (Fresen.) F. C. Harrison, and Saccharomyces cerevisiae Meyen ex Hansen. All isolates were cultivated on potato dextrose agar (PDA) at $23^{\circ} \mathrm{C}$ in complete darkness and were stored on PDA at $5^{\circ} \mathrm{C}$.

DNA extraction. Conidia from 5- to 8day-old cultures were removed aseptically by flooding each plate with $20 \mathrm{ml}$ of BGbroth $(0.5 \% \mathrm{wt} / \mathrm{vol}$ Bacto-Broth, $0.5 \%$ $\mathrm{wt} / \mathrm{vol}$ glucose) and scraping the surface. The conidial suspension was filtered through fiberglass into a conical flask and placed in an orbital shaker for $24 \mathrm{~h}$ at $20^{\circ} \mathrm{C}$. The germinated conidia were separated from the surrounding medium either by decanting or by filtrating the broth through muslin cloth and then drying the mycelium with paper towels. Samples of yeasts (Cryptococcus laurentii, $R$. glutinis, and $S$. cerevisiae) for DNA extraction were taken directly from PDA plates. Nucleic acids were extracted according to Möller et al. (13), except the volumes of all reagents were reduced by $60 \%$ and isopropanol replaced ethanol for DNA precipitation. All DNA extracts were quantified according to their optical density at $260 \mathrm{~nm}$, using a Spectronic Genesys 5 spectrophotometer (Milton Roy, Rochester, NY). DNA extraction was repeated at least twice for each isolate. 
RAPD analysis. Primers (10-mer) were selected at random from Operon primer kits A, B, and G (Operon Technology, Inc., Alameda, CA). Amplification reactions were done in a $20-\mu$ l reaction mixture containing 10 to $20 \mathrm{ng}$ of template DNA in $2.0 \mu \mathrm{l}$ of sterile distilled water, $2.0 \mu \mathrm{l}$ of $10 \times$ reaction buffer $(500 \mathrm{mM} \mathrm{KCl}, 100$ $\mathrm{mM}$ Tris- $\mathrm{HCl}[\mathrm{pH} 9.0]$, and $1 \%$ Triton; Promega Corp., Madison, WI), $2.0 \mu \mathrm{l}$ of dNTPs (each at $2.5 \mathrm{mM}$ ), $0.4 \mu \mathrm{l}$ of $\mathrm{Taq}$ DNA polymerase (5 U/ $\mu$; Promega Corp.), $2.0 \mu \mathrm{l}$ of $\mathrm{MgCl}(25 \mathrm{mM}), 5.0 \mu \mathrm{l}(30 \mu \mathrm{M})$ of primer, and $6.6 \mu \mathrm{l}$ of sterile distilled water. Samples were overlaid with mineral oil. Control reactions contained water instead of template DNA. Reactions were amplified in a programmable thermocycler (M. J. Research, Inc., Watertown, MA) for 45 cycles of $1 \mathrm{~min}$ at $94^{\circ} \mathrm{C}$ (melting), $30 \mathrm{~s}$ at $48^{\circ} \mathrm{C}$ (annealing), and $1.5 \mathrm{~min}$ at $72^{\circ} \mathrm{C}$ (extension), with a final extension at $72^{\circ} \mathrm{C}$ for $4 \mathrm{~min}$.

DNA was separated by electrophoresis in a $1.2 \%(\mathrm{wt} / \mathrm{vol})$ agarose gel in $1 \times \mathrm{TAE}$ buffer $(0.04 \mathrm{M}$ Tris-acetate, $0.001 \mathrm{M}$ EDTA, pH 8.0; 15). A 100-base pair (bp) ladder (Life Technologies, Gaithersburg, MD) was used as a size standard. To visualize DNA, gels were stained with ethidium bromide $(0.1 \mathrm{mg} / \mathrm{liter})$ and then photographed by transillumination using a Polaroid DS-34 with 667 film (Polaroid Corp., Cambridge, MA). All RAPD analyses were repeated at least three times for each isolate.

DNA polymorphism among isolates of $B$. cinerea and of epiphyte fungi. In a preliminary study to determine suitable primers, a total of 29 decaprimers (Table 1) were used to characterize two isolates of $B$. cinerea obtained from table grapes (G.4.1 and G4.4), and single B. cinerea isolates obtained from apples (A1.1) and blueberries (B2.1) were included. Additionally, single isolates of each of the following epiphytes were included for comparison: Alternaria alternata, Aspergillus niger, Cladosporium herbarum, Cryptococcus laurentii, E. nigrum, a Penicillium sp., Rhizopus stolonifer, and Rhodotorula glutinis.

Primers selected as useful in discriminating $B$. cinerea from other epiphyte fungi were used to study the uniformity and reliability of the amplification products from 25 additional isolates of $B$. cinerea from grapes and other hosts. As further controls, we examined one isolate of $S$. cerevisiae and two isolates each of Alternaria alternata, Aspergillus niger, and a Penicillium sp.

Genetic characterization of $\boldsymbol{B}$. cinerea from table grape. Genetic variability among isolates of $B$. cinerea from table grapes and from other host plants was assessed by RAPD analysis using 19 decaprimers selected from Operon Technologies kit A (OPAs: 1, 2, 9,12, 13, and 18), kit B (OPBs: 1, 7, 8, 10, 12, and 18), and kit G (OPGs: 2, 3, 7, 8, 9, 15, and 18) (Table 1), following the same protocol described above. Data were analyzed and scored as 0 or 1 based on the absence or that consistently appeared in standard positions. Data were analyzed statistically and a phenogram was constructed by the unweighted pair-group method with averages linkage (UPGMA) based on Jaccard similarity coefficients using the cluster analysis program NTSYS, PC version 2.01 .

Sensitivity of RAPD analysis. To study the relative sensitivity of the RAPD analysis in detecting conidia of $B$. cinerea, samples of B. cinerea (G.1.1), Alternaria alternata (Al6.2), Aspergillus niger (As4.2), and a Penicillium sp. (Pe1.2) were cultured for $48 \mathrm{~h}$ in BG-broth as described above. Germinated conidia (approximately 0.6 $\mathrm{mg}$ ) were then individually separated under a dissecting microscope and test samples composed of 1,3 , or 10 conidia of $B$. cinerea alone or in combination with three germinated conidia of the Penicillium sp. or with three germinated conidia each of Alternaria alternata, Aspergillus niger, and the Penicillium sp. were prepared. Control samples contained three germinated conidia of the Penicillium sp. alone, or sampresence, respectively, of DNA fragments ples containing three germinating conidia

of one of the fungi (Alternaria alternata, Aspergillus niger, and the Penicillium sp.). DNA extracted from each sample was then tested with primers OPA4 and OPA11.

\section{RESULTS}

DNA polymorphism among isolates of $B$. cinerea and of epiphyte fungi. Strong non-polymorphic fragments were PCR amplified consistently from the four isolates of $B$. cinerea with primers OPA4 $\left(\mathrm{Opa}_{1.30}\right)$ and OPA11 (Opa11 1.10 and Opa11 0.70 ) (Fig. 1). The other 27 primers produced variable results. Some primers amplified several strong fragments (e.g., OPAs 2 and 18 and OPBs 7 and 10) and others (e.g., OPBs 1, 8, 9, 15, and 18) produced common strong fragments of the same size as two or more of the fragments amplified from the epiphyte fungi. In a second test, fragments Opa $4_{1.30}$, Opa $11_{1.10}$, and Opa $11_{0.70}$ were also amplified from each of the 25 additional $B$. cinerea isolates obtained from table grapes and other hosts in different localities in Chile (Figs. 1 and 2).

With the exception of primer OPA11 with $R$. glutinis DNA, primers OPA4 and OPA11 generated banding patterns from each of the other fungal species that were easily distinguished from those of $B$. cinerea (Fig. 1).

Table 1. Sequences of primers used for random amplified polymorphic DNA analysis of Botrytis cinerea isolated from table grapes and other host plants in Chile

\begin{tabular}{|c|c|c|c|}
\hline \multirow[b]{2}{*}{ Primers $^{b}$} & \multirow{2}{*}{$\frac{\text { Nucleotide sequences }}{5^{\prime} \text { to } 3^{\prime}}$} & \multicolumn{2}{|c|}{ DNA fragments ${ }^{\mathrm{a}}$} \\
\hline & & Amplified & Polymorphic \\
\hline OPA1* & CAGGCCCTTC & 1 & 0 \\
\hline OPA $2 *$ & TGCCGAGCTG & 9 & 4 \\
\hline OPA4 & AATCGGGCTG & 1 & 0 \\
\hline OPA7 & GAAACGGGTG & 4 & 1 \\
\hline OPA8 & GTGACGTAGG & 2 & 0 \\
\hline OPA9* & GGGTAACGCC & 7 & 1 \\
\hline OPA11 & CAATCGCCGT & 2 & 0 \\
\hline OPA12* & TCGGCGATAG & 6 & 2 \\
\hline OPA13* & CAGCACCCAC & 2 & 0 \\
\hline OPA16 & AGCCAGCGAA & 2 & 0 \\
\hline OPA18* & AGGTGACCGT & 6 & 5 \\
\hline OPA20 & GTTGCGATCC & 2 & 0 \\
\hline OPB1* & GTTTCGCTCC & 5 & 2 \\
\hline OPB5 & TGCGCCCTTC & 1 & 0 \\
\hline OPB7* & GGTGACGCAG & 11 & 7 \\
\hline OPB8* & GTCCACACGG & 2 & 0 \\
\hline OPB $10 *$ & CTGCTGGGAC & 8 & 5 \\
\hline OPB11 & GTAGACCCGT & 1 & 0 \\
\hline OPB12* & CCTTGACGCA & 5 & 3 \\
\hline OPB14 & TCCGCTCTGG & 3 & 2 \\
\hline OPB15 & GGAGGGTGTT & 2 & 1 \\
\hline OPB18* & CCACAGCAGT & 2 & 1 \\
\hline OPG2* & GGCACTGAGG & 6 & 1 \\
\hline OPG3* & GAGCCCTCCA & 5 & 0 \\
\hline OPG7* & GAACCTGCGG & 5 & 3 \\
\hline OPG8* & TCACGTCCAC & 8 & 3 \\
\hline OPG9* & CTGACGTCAC & 2 & 1 \\
\hline OPG15* & ACTGGGACTC & 3 & 2 \\
\hline OPG18* & GGCTCATGTG & 4 & 2 \\
\hline Total & & 117 & $4 \overline{6}$ \\
\hline
\end{tabular}

a Total number of strongly stained and reproducible fragments and number of polymorphic fragments obtained among 15 isolates of $B$. cinerea.

${ }^{\mathrm{b}}$ Primers from Operon Technology (Alameda, CA) kits A, B, and G. Those primers followed by an asterisk were selected for genetic variability studies of isolates from table grapes and other host plants. 

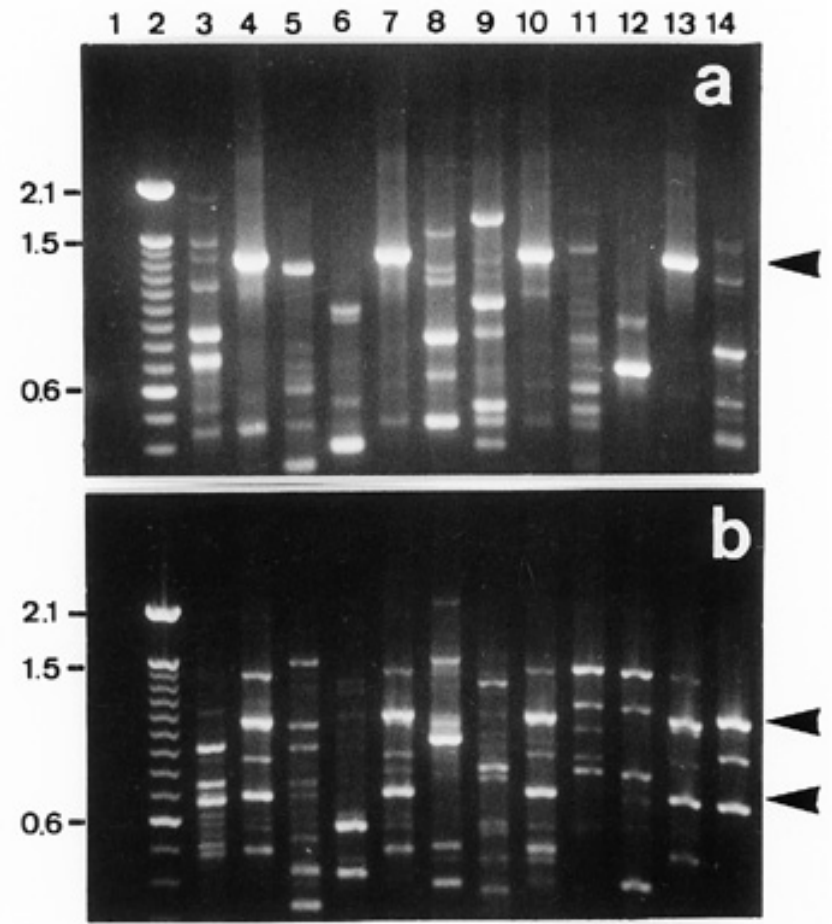

Fig. 1. Characterization of Botrytis cinerea and epiphyte fungi obtained from table grapes by random amplified polymorphic DNA analysis with primers (A) OPA4 and (B) OPA11. Isolates of $B$. cinerea from table grapes are in lanes 4 (G4.1) and 7 (G4.4), and those from apple and blueberry are in lanes 10 (A.1.1) and 13 (B.2.1), respectively. Lane 3, Alternaria alternata; lane 5, Aspergillus niger; lane 6, Cladosporium herbarum; lane 8, Cryptococcus laurentii; lane 9, Epicoccum nigrum; lane 11, a Penicillium sp.; lane 12, Rhizopus solonifer; and lane 14, Rhodotorula glutinis. Lane 1, distilled water and lane 2, 100-base pair molecular size marker in kilobases. The positions of fragments $\mathrm{Opa}_{1.30}, \mathrm{Opa} 11_{1.10}$, and Opa1 $1_{0.70}$ are marked with an arrow.

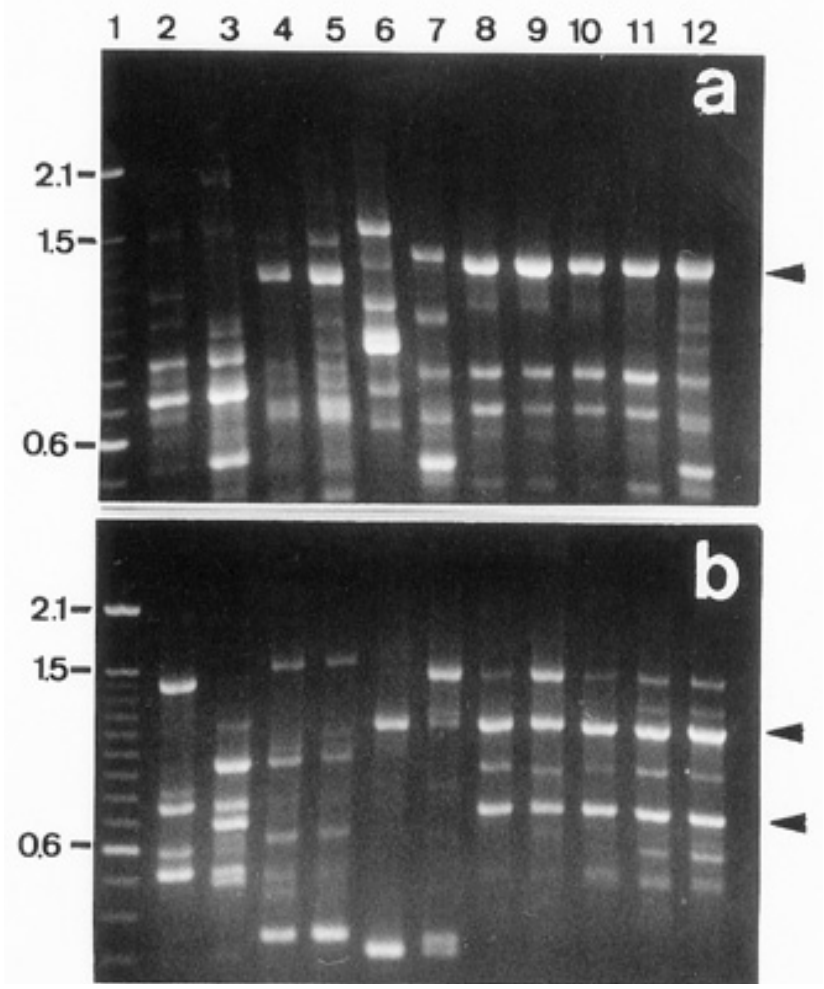

Fig. 2. Random amplified polymorphic DNA patterns obtained with primers (A) OPA4 and (B) OPA11 for isolates of Botrytis cinerea isolated from hosts other than table grapes and for isolates of epiphyte fungi commonly associates with table grape fruit clusters. Alternaria alternata isolates: lane 2, Al.6.2, and lane 3, A1.8.2; Aspergillus niger isolates: lane 4, As.4.2, and lane 5, As.9.2; Penicillium sp. isolates: lane 6, Pe.1.2, and lane 7, Pe.4.1; and B. cinerea: lanes 8 to 12, isolates from apple, lettuce, kiwifruit, pear, and tomato, respectively. Lane 1, 100-base pair molecular marker in kilo-

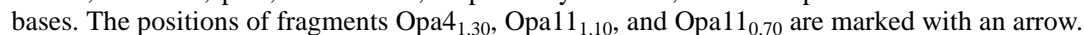

Genetic characterization of $B$. cinerea from table grape. A total of 97 strongly stained and reproducible fragments, 42 of which revealed polymorphism, were amplified from the 15 isolates of $B$. cinerea with the 19 primers (Table 1). These primers amplified 1 to 11 fragments per primer, ranging in size from 0.4 to 2.5 kilobases $(\mathrm{kb})$, although the majority were below 1.5 $\mathrm{kb}$. One to seven polymorphic fragments per primer were obtained with 15 of these primers. Similarity coefficients (SC) between pairs of isolates ranged from 0.326 to 0.891 (Table 2). The genetic distances among all 15 isolates of $B$. cinerea showed significant genetic variability and three main groups of isolates (I, II, and III) were identified (Fig. 3). Interestingly, each group consisted of isolates from different host plants. Group I contained all the isolates from table grapes, isolate P1 from pear, and isolates B1 and B4 from blueberry. Isolates from table grapes had SC values ranging from 0.761 to 0.891 and were distributed in subgroups Ia, Ib, or Ic, while the two isolates from blueberry were in subgroup Id and the pear isolate was in subgroup Ia. The SC values between isolates from table grapes and isolates B1 and B4 from blueberry varied from 0.326 to 0.826 (Table 2, Fig. 3). Group II contained the apple and tomato isolates and SC ranged from 0.717 to 0.848 . Group III contained isolates B2.2 and B2.3 (B2 and B3) from blueberry (SC: 0.673; Table 2).

Sensitivity of RAPD analysis. Using primer OPA11, fragment Opa $11_{1.10}$ was amplified from each test sample whether or not it contained DNA from $B$. cinerea. However, fragment Opa $11_{0.70}$ was amplified only from samples containing 1,3 , or 10 conidia of $B$. cinerea and from those containing 10 conidia of $B$. cinerea mixed with 3 conidia of either Alternaria alternata, Aspergillus niger, or the Penicillium sp. (Fig. 4). The results obtained with primer OPA4 were not specific, because this primer amplified a fragment the size of $\mathrm{Opa}_{1.30}$ from Penicillium sp. isolate Pe1.2.

\section{DISCUSSION}

RAPD analysis was a useful tool for characterizing genetic variability among isolates of $B$. cinerea from table grapes and other hosts. Significant genetic variability was observed among 15 different isolates of $B$. cinerea, using 19 arbitrary oligonucleotide primers with $\mathrm{SC}$ values ranging from 0.326 to 0.891 (Table 2). Similar variability and SC values were previously reported for $B$. cinerea populations obtained on hosts other than table grapes, suggesting a great genetic diversity among isolates of $B$. cinerea $(10,14,16)$. No relationship was found between geographical origin and the DNA profiles obtained. However, based on the genetic similarities, the cluster analysis divided the 15 isolates of $B$. cinerea into three main groups. Interestingly, all isolates from table grapes were 
included in group I, isolates from apple and tomato were in group II, while isolates from blueberry were either in group I (subgroup Id) or in group III (Fig. 3). It is generally accepted that no host specialization occurs among $B$. cinerea populations because isolates of $B$. cinerea can infect a wide range of host plants in the laboratory (9). Nevertheless, it is still possible that host specificity may occur in the field, and our results support this hypothesis. Similar results were reported previously in Chile using RAPD analysis (14), and results obtained with other molecular techniques showed great genetic diversity among $B$. cinerea isolates, also suggesting host specialization in $B$. cinerea populations $(3,4,6,8)$. Consequently, isolates from table grapes may be genetically distinct from isolates of $B$. cinerea obtained on other hosts. Nevertheless, additional studies

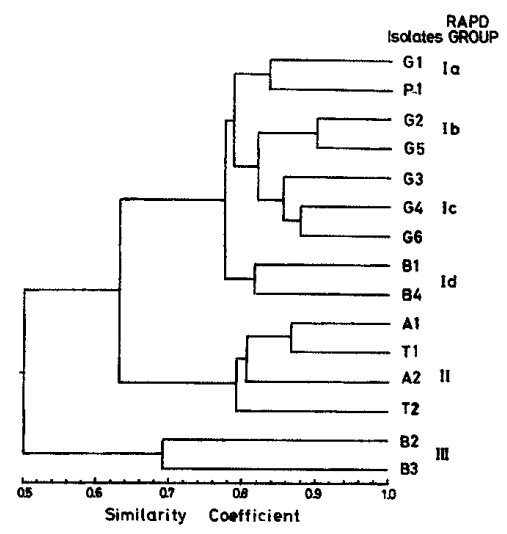

Fig. 3. Phenogram based on random amplified polymorphic DNA profiles (RAPD) showing the genetic relationships among 15 isolates of Botrytis cinerea isolated from different host plants in Chile that were generated with 19 arbitrary decaprimers. Isolates G1 to G6 were from table grapes, A1 and A2 from apple, B1 to B4 from blueberry, P1 from pear, and T1 and $\mathrm{T} 2$ from tomato. using a rather large number of $B$. cinerea isolates would be advisable in order to clarify the pathological significance of these RAPD groups.

The experiments to test the sensitivity of the RAPD analysis using primers OPA4 and OPA11 were designed to include the range of fungi likely to be encountered when grape clusters are sampled. The choice of using Alternaria alternata, Aspergillus niger, and a Penicillium sp. in the extraction with $B$. cinerea was based on the high frequency of occurrence of these fungi on grape clusters as previously reported in Chile and elsewhere $(7,12)$. For OPA4 and OPA11, even one germinated conidium could be detected by this method, although competition presumably from excess DNA from other sources during amplification results in no fragment being detected. In the case of primer OPA4, the results showed that the fragment
Opa $_{1.30}$ was not specific, because it appeared with varying degrees of intensity in all extracts, including those without $B$. cinerea, most likely because of a minor band of the same size produced by the Penicillium sp. sample. With primer OPA11, fragment Opa11 1.10 or a fragment of the same size was present in all extracts. Fragment Opa11 $1_{0.70}$ could only be detected in those samples containing B. cinerea, and it was absent in fungal mixes with only one germinated conidia of $B$. cinerea. Taking into account the amount of inter- and intraspecific variation detected in this study, it can be assumed that the chance of there being a fungal source that is not $B$. cinerea, producing a fragment of similar or identical size to that of one found in all B. cinerea isolates, is relatively low. Nevertheless, this fragment should be cloned, sequenced, and specific primers designed before it is used to detect $B$. cinerea.

\section{$\begin{array}{llllllllllll}1 & 2 & 3 & 4 & 5 & 6 & 7 & 8 & 9 & 10 & 11 & 12\end{array}$}

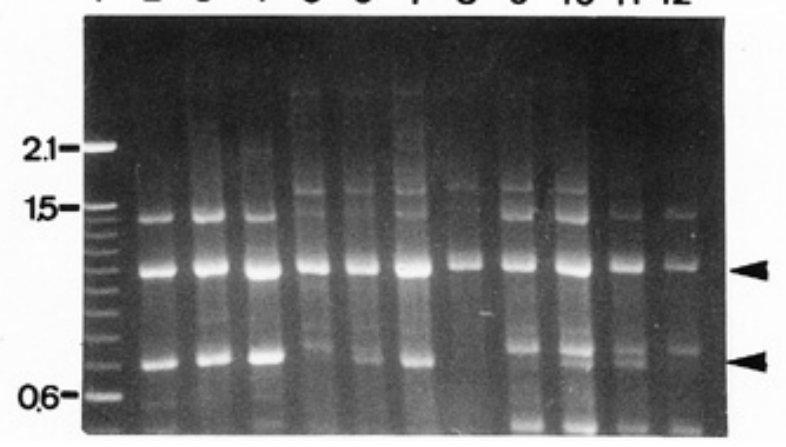

Fig. 4. Sensitivity of the random amplified polymorphic DNA analysis using primer OPA11 to detect Botrytis cinerea. Lanes 2, 3, and 4, test samples containing DNA from 1, 3, or 10 germinated conidia of B. cinerea (G.9.1) alone, respectively; lanes 5, 6, and 7, in mixed samples containing DNA from 1, 3 , or 10 germinated conidia of $B$. cinerea and from three germinated conidia of Penicillium $s p$. (P1.2), respectively; or lanes 9, 10, and 11, from germinated conidia of each Alternaria alternata (A16.2), Aspergillus niger (As4.2), and Penicillium sp., respectively. Lane 1, 100-base pair molecular size marker indicated in kilobases. Lane 8, DNA from three germinated conidia of the Penicillium sp. alone. Lane 12, DNA from three germinated conidia each of Alternaria alternata (Al6.2), Aspergillus niger (As4.2), and the Penicillium sp. (Pe1.2). The positions of fragments Opa11 $1_{1.10}$ and Opa $11_{0.70}$ are marked with an arrow.

Table 2. Similarity coefficients for isolates of Botrytis cinerea isolated from table grape and other host plants in Chile ${ }^{\mathrm{a}}$

\begin{tabular}{|c|c|c|c|c|c|c|c|c|c|c|c|c|c|c|c|}
\hline \multirow[b]{3}{*}{ Isolates } & \multicolumn{15}{|c|}{ Host origin of isolates } \\
\hline & \multicolumn{6}{|c|}{ Table grapes } & \multicolumn{4}{|c|}{ Blueberries } & \multicolumn{2}{|c|}{ Apples } & \multirow{2}{*}{$\begin{array}{c}\text { Pear } \\
\text { P2 }\end{array}$} & \multicolumn{2}{|c|}{ Tomatoes } \\
\hline & G1 & G2 & G3 & G4 & G5 & G6 & B1 & $\mathbf{B 2}$ & B3 & B4 & $\mathbf{A 1}$ & $\mathbf{A 2}$ & & T1 & T2 \\
\hline G1 & 1 & & $\ldots$ & $\ldots$ & $\ldots$ & $\ldots$ & $\ldots$ & $\ldots$ & $\ldots$ & $\ldots$ & $\ldots$ & $\ldots$ & $\ldots$ & $\ldots$ & $\ldots$ \\
\hline G2 & 0.826 & 1 & $\ldots$ & $\ldots$ & $\ldots$ & $\ldots$ & $\ldots$ & $\ldots$ & $\ldots$ & $\ldots$ & $\ldots$ & $\ldots$ & $\ldots$ & $\ldots$ & $\ldots$ \\
\hline G3 & 0.826 & 0.870 & 1 & $\ldots$ & $\ldots$ & $\ldots$ & $\ldots$ & $\ldots$ & $\ldots$ & $\ldots$ & $\ldots$ & $\ldots$ & $\ldots$ & $\ldots$ & $\ldots$ \\
\hline G4 & 0.804 & 0.848 & 0.848 & 1 & $\ldots$ & $\ldots$ & $\ldots$ & $\ldots$ & $\ldots$ & $\ldots$ & $\ldots$ & $\ldots$ & $\ldots$ & $\ldots$ & $\ldots$ \\
\hline G5 & 0.761 & 0.891 & 0.804 & 0.783 & 1 & $\ldots$ & $\ldots$ & $\ldots$ & $\ldots$ & $\ldots$ & $\ldots$ & $\ldots$ & $\ldots$ & $\ldots$ & $\ldots$ \\
\hline G6 & 0.761 & 0.761 & 0.848 & 0.870 & 0.783 & 1 & $\ldots$ & $\ldots$ & $\ldots$ & $\ldots$ & $\ldots$ & $\ldots$ & $\ldots$ & $\ldots$ & $\ldots$ \\
\hline B1 & 0.783 & 0.739 & 0.826 & 0.804 & 0.717 & 0.761 & 1 & $\ldots$ & $\ldots$ & $\ldots$ & $\ldots$ & $\ldots$ & $\ldots$ & $\ldots$ & $\ldots$ \\
\hline B2 & 0.391 & 0.348 & 0.348 & 0.370 & 0.326 & 0.413 & 0.435 & 1 & $\ldots$ & $\ldots$ & $\ldots$ & $\ldots$ & $\ldots$ & $\ldots$ & $\ldots$ \\
\hline B3 & 0.500 & 0.457 & 0.500 & 0.435 & 0.478 & 0.435 & 0.500 & 0.673 & 1 & $\ldots$ & $\ldots$ & $\ldots$ & $\ldots$ & $\ldots$ & $\ldots$ \\
\hline B4 & 0.717 & 0.761 & 0.804 & 0.826 & 0.696 & 0.783 & 0.804 & 0.457 & 0.565 & 1 & $\ldots$ & $\ldots$ & $\ldots$ & $\ldots$ & $\ldots$ \\
\hline A1 & 0.652 & 0.652 & 0.696 & 0.630 & 0.630 & 0.587 & 0.652 & 0.435 & 0.587 & 0.630 & 1 & $\ldots$ & $\ldots$ & $\ldots$ & $\ldots$ \\
\hline A2 & 0.674 & 0.587 & 0.587 & 0.609 & 0.609 & 0.565 & 0.630 & 0.543 & 0.609 & 0.609 & 0.761 & 1 & $\ldots$ & $\ldots$ & $\ldots$ \\
\hline P2 & 0.826 & 0.783 & 0.783 & 0.717 & 0.761 & 0.717 & 0.696 & 0.435 & 0.543 & 0.717 & 0.739 & 0.717 & 1 & 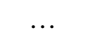 & $\ldots$ \\
\hline $\mathrm{T} 1$ & 0.587 & 0.544 & 0.544 & 0.522 & 0.522 & 0.565 & 0.500 & 0.587 & 0.478 & 0.565 & 0.717 & 0.739 & 0.674 & 1 & $\ldots$ \\
\hline $\mathrm{T} 2$ & 0.630 & 0.674 & 0.674 & 0.696 & 0.652 & 0.652 & 0.630 & 0.543 & 0.652 & 0.696 & 0.848 & 0.826 & 0.717 & 0.826 & 1 \\
\hline
\end{tabular}

a Similarity coefficients were calculated based on Jaccard similarity coefficients from DNA profiles obtained with decaprimers OPAs 1, 2, 9, 12, 13, and 18; OPBs 1, 7, 8, 10, 12, and 18; and OPGs 2, 3, 7, 8, 9, 15, and 18 (Operon Technologies, Alameda, CA). 


\section{ACKNOWLEDGMENTS}

We thank B. Ford-Lloyd, Birmingham University, England, for his help with the statistical analysis; P. Arce, Pontificia Universidad Católica, Chile, for his advice; and A. L. Jones, Michigan State University, for critically reviewing the manuscript.

\section{LITERATURE CITED}

1. Broome, J. C., English, J. T., Marois, J. J., Latorre, B. A., and Aviles, J. C. 1995. Development of an infection model for Botrytis bunch rot of grapes based on wetness duration and temperature. Phytopathology 85:97-102.

2. Bulit, J., and Dubos, B. 1988. Botrytis bunch rot and blight. Pages 13-15 in: Compendium of Grape Diseases. R. C. Pearson and A. C. Goheen, eds. The American Phytopathological Society, St. Paul, MN.

3. Büttner, P., Koch, F, Volgt, K., Quidde, T., Rish, S., Blaich, R., Brückner, B., and Tudzynski, P. 1994. Variations in ploidy among isolates of Botrytis cinerea: implications for genetic and molecular analysis. Curr. Genet. 25:445-450.

4. Derckel, J. P., Baillieul, F., Manteau, S., Audran, J. C., Haye, B., Lambert, B., and Legendre, L. 1999. Differential induction of grapevine defenses by two strains of Botrytis cinerea. Phytopathology 89:197203.

5. Di Lenna, P., Marciano, P., and Magro, P. 1981. Comparative investigation on morphological features of three isolates of Botrytis cinerea. Phytopathol. Z. 100:203-211.

6. Diolez, A., Marches, F., Fortini, D., and Brygoo, Y. 1995. Boty, a long-terminal-repeat retroelement in the phytopathogenic fungus Botrytis cinerea. Appl. Environ. Microbiol. 61:103-108.

7. Duncan, R. A., Stapleton, J. J., and Leavitt, G. M. 1995. Population dynamics of epiphyte mycoflora and occurrence of bunch rots of wine grapes as influenced by leaf removal. Plant Pathol. 44:956-965.

8. Giraud, T., Fortini, D., Levis, C., Leroux, P., and Brygoo, Y. 1997. RFLP markers show genetic recombination in Botryotinia fuckeliana (Botrytis cinerea) and transposable elements reveal two sympatric species. Mol. Biol. Evol. 14:1177-1185.

9. Jarvis, W. R. 1980. Epidemiology. Pages 219239 in: The Biology of Botrytis. J. R. ColeySmith, K. Verhoef, and W. R. Jarvis, eds.. Academic Press, London, UK.

10. Kerssies, A., Bosker-van Zessen, A. I., Wagemakers, C. A. M. and van Kan, J. A. L. 1997. Variation in the pathogenicity and DNA polymorphism among Botrytis cinerea isolates sampled inside and outside a glasshouse. Plant Dis. 18:781-786.

11. Latorre, B. A. 1986. Manejo de Botrytis cinerea en uva de mesa. Rev. Frutícola (Chile) 7:75-83.

12. Latorre, B. A., and Vásquez, G. 1996. Situación de Botrytis cinerea latente en uva de mesa de la zona Central. Aconex (Chile) 52:16-21.

13. Möller, E. M., Bahnweg, G., Sandermann, H., and Geiger, H. H. 1992. A simple and efficient protocol for isolation of high molecular weight DNA from filamentous fungi, fruit bodies, and infected plant tissues. Nucleic Acids Res. 20:6115-6116

14. Muñoz, G., Hinrichsen, P., and Alvarez, M. 1999. Variabilidad genética de cepas de Botrytis cinerea provenientes de vid y tomate con resistencia a dicarboximidas. Agric. Técnica (Chile) 59:1-12.

15. Sambrook, J., Fritsch, E. F., and Maniatis, T. 1987. Molecular Cloning: A Laboratory Manual. 2nd ed. Cold Spring Harbor Laboratory, Cold Spring Harbor, NY.

16. Van der Vlugt-Bergmans, C. J. B., Brandwagt, B. F., van't Klooster, J. W., Wagemakers, C A. M., and van Kan, J. A. L. 1993. Genetic variation and segregation of DNA polymorphism in Botrytis cinerea. Mycol. Res. 97:1193-1200.

17. Welsh, J., Petersen, C., and McClelland, M. 1991. Polymorphisms generated by arbitrarily primed PCR in mouse: application to strain identification and genomic mapping. Nucleic Acids Res. 19:303-306.

18. Williams, J. G. K., Kubelik, A. R., Livak, K. J., Rafalski, J. A., and Tingey, S. V. 1990 DNA polymorphisms amplified by arbitrary primers are useful as genetic markers. Nucleic Acids Res. 18:6531-6535

19. Zalewska-Sobczak, J., Boreka, H., and Urbanek, H. 1981. Comparison of pectinase, xylanase and acid protease activities of virulent and less virulent isolates of Botrytis cinerea. Phytopathol. Z. 101:222-227. 